Journal of Social Sciences 4 (2): 98-102, 2008

ISSN 1549-3652

(C) 2008 Science Publications

\title{
Small-Scale Industries in Jordan in the Globalization Era Performance and Prospects
}

\author{
Basem Mohammed Lozi \\ Amman College for Administrative and Financial Sciences, \\ Al Balga Applied University, Jordan
}

\begin{abstract}
The research probes the implications of globalization and domestic economic liberalization for small-scale industries and analysis its growth performance. The research concludes with policy recommendations to ensure the sustenance and competitive growth of small-scale industries in Jordan. Results of the study show that the growth of small scale industries in Jordan in terms of units, employment, output and exports has come up due to globalization, domestic liberalization and dilution of sector specific measures. The government should involve the private sector in the development of infrastructure, to enable efficient monitoring and good facilities to the small scale industries. There is a need to create fund at the government level for disbursement as margin money through district industries centers to small scale industries units to encourage them to undertake technological innovations. A technological vibrant, internationally competitive small scale industries sector should be encouraged to emerge, to make a sustainable contribution to national income, employment and exports.
\end{abstract}

Keywords: Small scale industries, policy, globalization, Jordan, competitiveness

\section{INTRODUCTION}

Small scale industry sector occupies a place of strategic importance in Jordanian economy structure due to its considerable contribution in terms of output, exports and employment. Small scale industries play a key in the industrialization and development of a country. This is because they provide immediate large scale employment comparatively higher capital ratio, they need lower investment, offer a method of ensuring a more equitable distribution of national income and facilitate an effective mobilization of resources, capital and skill which might other wise remain unutilized ${ }^{[4]}$. Development of small scale industries was governorate affair therefore, these industries were planned by the governorates. The governorate co-ordinate the development programs through its agencies.

Small scale industries sector was a major contributor to the industrial economy of Jordan. It accounts for $50 \%$ of the total manufacturing sector, has $20 \%$ share in exports and provides $80 \%$ of employment in industrial sectors ${ }^{[10]}$. In spite of all the odds it has always performed well. Despite the global and domestic recession, small scale industries registered a higher growth rate when the overall industrial sector in terms of number of units. Liberalization have forced all industries to constantly up grade their quality while cutting down the costs if they want to remain and retain their place and share in the global market. Small scale industries world over including Jordan were facing the on slight of the adverse effects of globalization in the stringent requirements of quality costs, tight delivery schedules and productivity ${ }^{[1]}$.

\section{MATERIALS AND METHODS}

This research is based on the survey and analysis of secondary data, the data was a gathered from published studies and reports available in English and in Arabic. Relevant statistics were obtained from Central Bank of Jordan and Department of Statistics. The answer to the following questions is one of the objectives of this study

- Why global and national policy development should affect small business scale industries in Jordan? How? What are its implications?

- How far small scale industries have been able to cope up with the competitive environment? What was its growth performance in the last decade? How different was it compared to the earlier decades?

- What are the future prospects of small scale industries in Jordan in the era of globalization? What steps need to be taken to strengthen small scale industries to ensure its sustained contribution to Jordanian economy? 


\section{RESULTS AND DISCUSSIN}

The over all performance and contribution of small scale industries to Jordanian economy is generally described in terms of its absolute growth in units, employment, production and exports. Equally important is its relative contribution, which can be analyzed in terms of its share in the national income, total exports and total organized sector employment. Thus, the growth of small scale industries can be evaluated in two ways:

- To compare the growth rates of units, employment, output and exports of small scale industries in the 2000 with that of 1990 s

- To ascertain the change in the relative contribution of small scale industries to GDP, exports and organized sector employment in the 2000s with that of 1990 s

This will reveal how the sector is copying up with challenges and changes in the intensifying competitive environment emerging since 1990-1991. The growth of small scale in terms of units, employment, production and exports is estimated based on the figures given in bulletins issued by the Central Bank of Jordan (CBJ) and Department of Statistics (DOS). The share of small scale industries in National Income is arrived at as follows: The Gross Value Added (GVA) of firms having investment more than that of the small scale industries investment limit is deducted from the manufacturing sector's contribution to Gross Domestic product (GDP) and the remainder is the contribution of small scale industries to GDP. This value is calculated as a percentage of the total GDP.

The growth rates of small scale industries in terms, of units, employment, output and exports for the 1990s and 2000s are percentage in table 1.

It is clear that the growth of small scale industries has come up in terms of not only units and employment, but also in terms of output. This could be an indication that increasing competition in the globalization period and the agreements signed with other affected the growth of Jordanian small scale industries positively. Growth rates are estimated for 5 years period. The growth rates of units, employment, output and exports steadily come up. In fact, the growth rate increased in the 2000s as compared to early 1990s.

The other dimension of small scale industries is its relative contribution to national income (GDP). The contribution of small scale industries is considered for four periods of time: 1990, 1995, 2000 and 2005 (Table 2).
Table 1: Growth of small scale industries (1990s and 2000s)

\begin{tabular}{lllll}
\hline Export & Output & Employment & Units & Period \\
\hline 10.5 & 13.2 & 4 & 5.2 & $1995-1990$ \\
15.9 & 15.3 & 8.3 & 7.3 & $1996-2000$ \\
25.3 & 19.3 & 10.2 & 9.5 & $2001-2005$ \\
\hline
\end{tabular}

Source: Department of Statistics, Annual statistical Bulletin, (various issues)

Table 2: Small scale industries in Jordan's national income (GDP) in percent

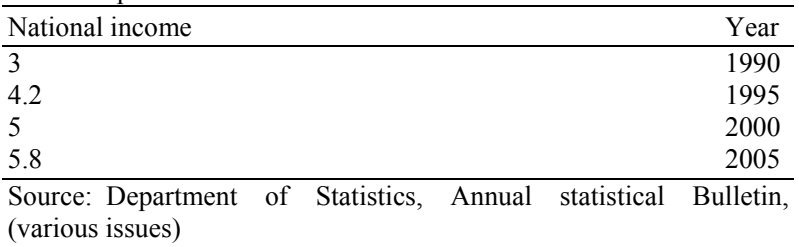

The share of small scale industries in national income has consistently increased. The infrastructure constraints confronted by small scale industries can be broadly classified as economic, technological, marketing and financial. Stable and reliable economic infrastructure such as power, water, transport and communications are a pre-requisite for the official functioning of any economic activity including small scale industries. Inadequate economic infrastructure is one major factor affects the performance and competitiveness of small scale industries. It is to overcome the infrastructural deficiencies faced by the sector, particularly in rural/backward areas and to strengthen linkages between agriculture and industry the government introduced many schemes. The purpose of there schemes is to contain developed sites, power distribution network, water, telecommunications, drainage and pollution control facilities, roads, banks, raw material depots, storage and marketing, outlets, common facilities and technological back-up services. Recently, the government of Jordan has proposed to extend these schemes to the entire country ${ }^{[5]}$. However, it is not clear how and when the schemes will be expended to cover the entire country.

The need for improving the competitive strength of small scale industries through technology improvement and modernization was recognized as early as in the 1990 s with the setting up of small industries development programs ${ }^{[6]}$. Since then, over a period of time, particularly in the 2000 s exclusive technology infrastructure has come up for small scale industries to facilitate technology transfer. Thus, policy makers in Jordan have considered technology development in small scale industries only from a single dimension, that is, through institutional technology transfer.

How far technological infrastructure meant for small scale industries has helped them in another issue. Technology development in small scale industries can 
be achieved through in-house technological innovations as well as inter-firm linkages with large firms ${ }^{[2]}$. Technological innovation involves the situationally new development and introduction of knowledge- derived tools, artifacts and devices by which people extend and interact with their environment. It is primarily rooted in a firm's internal competencies. The advantage with inhouse technological innovations is that it can be firm specific and continuous. Similarly, a small firm can get technological inputs and technology through subcontracting relationship with large firms on a continuous basis. In Japan, effective sub-contracting relationship between small and medium enterprises and large firms works as an important mechanism of technology transfer ${ }^{[3]}$. But in Jordan, policy seems to have over looked the ability of small firms to innovate and the extent of ancillarisation, through increasing in recent years, is well below potential.

Timely availability of adequate finance is another issue, which crucially determines the survival and growth of small firms. Small firms are largely dependent on bank credit to meet their financing requirements while the big firms have alternative sources of finance ${ }^{[13]}$. To ensure better financial infrastructure, government of Jordan directed its institutions and commercial banks to meet the working capital needs of small scale industries at a very low interest rate ${ }^{[12]}$. However, despite the development of exclusive financial infrastructure for small scale industries, the growth in the amount of credit extended to small scale industries is not sufficient.

Marketing has been identified as one of the major problem areas of the small scale industries and it has been ranked as the second most reason for the closure of small scale units ${ }^{[8]}$. It is quite logical and obvious, if small firms do not have access to reliable and efficient economic infrastructure, they suffer, in general, from technological obsolescence and if credit flow is not sufficient, they will not be able to produce quality goods and productivity will not be higher either. In such a case, small firms will not be able to penetrate markets, national or international, even if marketing support is coming from government agencies. After 1990s, two major steps have been taken by the government to promote small scale industries marketing:

- The scheme of establishing strong relation between small and large firms, one of the major objectives of this scheme is to provide good in formations by large scale industries to the small scale industries about the new method of marketing and low to take chance in the international market
- With a view to ensure that exports from small scale industries sector exhibit their produces in the International Exhibitions, required assistance and support is provided. Expenditure on account of space rent, handling and clearing changes, insurance and shipment charges, etc., are met by the government of Jordan under one of the plan schemes

Thus, the current status of small scale industries in Jordan can be appropriately understood in the above context. Given the good performance of small scale industries in the context of constraints, it is essential to ponder over its future prospects and the strategy to be adopted by the stakeholders; namely, the government and more importantly the small scale industries sector itself.

Based on the data analysis the research concluded the following results:

- First of all, if small scale industries have to thrive steadily, infrastructural bottlenecks must be overcome to enable them to compete based on their internal potential. And it is the responsibility of the government to remove any structural bottleneck for small scale industries performance especially when market forces are given prominence through the removal of protective elements. It is essential to provide the much-needed level playing field to small enterprises through infrastructure development. But overcoming the infrastructural bottlenecks' for small scale industries is easier said than done

- To enable efficient monitoring and provision of infrastructural facilities, small scale industries should be permitted to come days only in designated industrial areas or estates. Each state should be asked to develop a database of small scale industries, which should be up dated at least, once in three years. There will facilitate policy corrections from time to time. In addition, the government along with industry associations should involve the private sector in the development of infrastructure in existing industrial areas and clusters and permit provision of infrastructural services on payments. Similarly, private sector investment should be encouraged for the development and management of existing as well as new industrial parks and clusters. These steps would go along may in strengthening the infrastructure for small scale industries development in Jordan 
- There is a need to explicitly recognize and exploit the innovation potential of small scale industries. In developed countries small scale industries are promoted, among others. Small scale enterprises have the specific advantages of flexibility, concentration and internal communications for carrying out technological innovations. Technological innovations contribute to competitiveness. Even in the Jordanian context a significant number of small firms do carry out technological innovations and there by enhance their competitiveness. Therefore, it is appropriate to incorporate schemes in the existing policy and institutional network to provide technological and financial assistance to in-house technological innovations at the district level and make it easily accessible to small scale industries. There is a need to create fund at the government level for disbursement as margin money through district industries centers to small scale industries units to encourage them to undertake technological innovations

- These schemes are not to undermine the significance of the present strategy of technology transfer. It essential to pursue with more intensity the existing strategy of technological up gradation and modernization by involving governorates and small scale industries associations, particularly with a focus on small scale industries clusters.

- There is a need for technological transformation of Jordanian small scale industries is gigantic task and government alone cannot achieve the objective, however extensive its infrastructure may be. Therefore major initiative has to come from small scale industries itself, particularly through their associations. The importance of achieving and sustaining competitiveness in the long and investing self-efforts and resources needs to be realized and spread among small scale industries units through their associations at regional level. This will play a good role in their long-term development in the future.

- The increase in the competitiveness of small scale industries will also be determined by the availability and quantum of finance. The demand for finance- implicit as well explicit-from small scale industries will be substantial considering its size, structure, growth pattern need for its reconstructing and technology development. Particularly, the investment demand for finance from small scale industries will increase considerably due to technology and modernization, expansion quality, improvement and technological innovations, environment related investments, etc. To meet the growing and diversified and specifically to take care of the technological transformation of small scale industries and lay more thrust on adequate flow of finance to the sector. The promotion of inter firm linkages is another issue deserving more recognition.Till recently small and medium-sized enterprises in general were precluded from participating in the lucrative supply-chain transactions generated by much larger manufacturers and suppliers. In most cases small and medium enterprises were unaware or unable or unwilling to spend the necessary capital or transactional system implementations, or infrastructure upgrades. However, time is changing now. The increasing presence of transnational corporations in the country would open up new opportunities for sub-contracting/ outsourcing. This is because FDI has flowed into industries such as telecommunications, transportation, where opportunities for sub-contracting/ outsourcing are high for small scale industries.

- Globalization need not affect Jordanian small Scale Industries adversely. It would have created beneficial opportunities as well. The removal of quantities restrictions and reduction of import duties, particularly after the setting up of WTO in 1995, have opened up foreign markets to Jordanian small scale industries as much as Jordanian market to foreign goods[7]. Many efficient and export oriented small firms in Jordan to enhance their competitiveness to penetrate the global market. This could also be achieved by small firms becoming vendors or sub-contactors to foreign large scale industries. The trend is outsourcing of supplies by Transnational Corporations and they are always on the look out for firms who could supply reliable and quality products.

- Finally, irrespective of the degree of support extended by the government, Jordan is going to experience the emergence of small scale industries sector, which is qualitatively superior, technologically vibrant and internationally competitive, in the next five-to-ten years because the inefficient ones are likely to vanish gradually. The objective of the policy makers as well as scale industries associations should be to enable the sector to emerge vibrant and competitive without a considerable reduction in its size and thereby enable it to make a sustainable contribution to national income, output and exports. 


\section{CONCLUSION}

Small scale industries in Jordan find itself in an intensely competitive environment since 1991 due to globalization domestic economic liberalization and dilution of sector specific protective measures. As a result, its growth in terms of units, employment, output and exports has come up. This has resulted in more growth in its contribution to national income and exports in the 1990s. International and national policy changes have thrown open new opportunities and markets to Jordanian small scale industries. Concerted efforts are needed both from the government and more importantly, from small scale industries themselves to imbibe technological dynamism into Jordanian small scale industries. Technological up gradation and inhouse technological innovations and promotion of interfirm linkages need to be encouraged consciously and consistently. The benefits and need to go for technology development through either technology transfer or technological innovations or inter-firm linkages should be emphasized in the light of dimensions of global competition and its negative fall outs as well as positive opportunities, to small scale industries entrepreneurs through seminars and work shop, at the local level. Financial infrastructure needs to be broadened and adequate inflow of credit to the sector ensured taking into consideration the growing investment demand including the requirements of technological transformation. Small scale industries should be allowed to come up only in designated industrial areas for better monitoring and periodic surveys though Ministry of industry should enable policy corrections from time to time. A technological vibrant, internationally competitive small scale industries sector should be encouraged to emerge, to make a sustainable contribution to national income, employment and exports.

\section{REFERENCES}

1. Stiglitz, J., 2002. Globalization and its Discontents. The Penguin Press, London, UK.

2. Subramanian, K.K., 1995. Technology dimensions of small scale industry. Productivity, 36 (1): 26-30.

3. Lakaka, R., 2003. Business Incubators in Developing Countries. NY10028, Vol 3, New York, USA.

4. Hakura, D., 2004. Growth in the Middle East and North Africa. IMF, Working Paper No. 56.

5. Abed, G., 2003. Unfulfilled promise: Why the Middle East and North Africa has lagged in growth and globalization. Finance Dev., 40: 10-14.

6. Bencivenga, V., S. Bruce and R. Starr, 1995. Transaction costs, technological choice and endogenous growth. J. Econ. Theory, 67: 53-117.

7. Chan, K. and E. Gemayal, 2004. Risk Instability and the Pattern of Foreign Direct Investment in the Middle East and North Africa. IMF, pp: 139.

8. Sala-i-Martin, X. and E. Artadi, 2002. Economic Growth and Investment in the Arab World. Columbia University, Department of Economics, Discussion Paper Number 0202 08, (New York: Columbia University).

9. Economic and Social Commission for Western Asia, 1992. The impact of the Gulf Crisis on the Jordanian Economy. E/ESCWA/DPD/1992/5.

10. Central Bank of Jordan, Monthly Statistical Bulletin, (various issues).

11. Department of Statistics, Annual statistical Bulletin, (various issues).

12. Ministry of Planning, 1993. Five year plan for economic and social development 1993-1997, Amman.

13. Chuta, E. and S.V. Sethuraman, 1984. Rural smallscale industries and employment in Africa and Asia Geneva, 120: 144-149. 